\title{
Antimicrobial Activity of Denture Adhesives Against Lactobacillus, Streptococcus mutans, Candida albicans
}

\author{
Deepika. $R^{1}$ and N.P. Muralidharan ${ }^{2}$ \\ ${ }^{1}$ Saveetha Dental College \&t Hospitals, Saveetha Institute of Medical and \\ Technical Sciences, Saveetha University, Chennai-77Tamilnadu, India. \\ ${ }^{2}$ Professor, Department of Microbiology, Saveetha Dental College \& Hospitals, Saveetha Institute \\ of Medical and Technical Sciences, Saveetha university Chennai-77, Tamilnadu, India.
}

\section{ABSTRACT}

Denture Stomatitis is a common issue in denture wearers. It is mainly due to its continued use. Once when the patient finds it uncomfortable discontinue the usage. Prevention of mucositis or stomatitis is very important in the denture wearers. It can be prevented by maintaining proper oral hygiene. But in immunocompromised state it is very difficult to maintain especially in old age patients. Denture adhesives are normally used by the denture wearers to have the denture firmly fixed in the mouth. This can be used to prevent the formation of denture stomatitis in the patients. Two types of materials are used by the patients, gel form and powder form adhesives. This study is done to find out the antimicrobial activity of the denture adhesives against the common organisms associated with Denture stomatitis. The antimicrobial effect of the denture adhesive is tested with 3 organisms, C.albicans, S. mutans and Lactobacillus. The anti microbial activity was tested by agar well diffusion method. The media used are, SDA agar and TSA. Wells were cut with a sterile steel tube. TSA was used for Lactobacilli and S. mutans and SDA was used for C.albicans. On each plate 3 wells were cut and the adhesives were filled in it. The adhesives were mixed in sterile Petri dishes and allowed to expand. Thus it was transferred to the well after coating the agar surface with the organism. Then the plates were incubated at 37 degree $\mathrm{C}$ for $12 \mathrm{hrs}$ and examined for the zone of inhibition around the well. The zone was measured with a scale and tabulated. The results were obtained as for powder the zone of inhibition in Lactobacillus was $11 \mathrm{~mm}$, zone of inhibition for powder in C.albicans was $14 \mathrm{~mm}$ and the zone of inhibition for powder in S.mutans was $10.5 \mathrm{~mm}$ which showed a better anti microbial activity for denture adhesive in powder form whereas for gel form the zone of inhibition was not seen. In this study with the 2 products tests, powder has more antimicrobial activity than gel and found to be active against Lactobacillus, Candida albicans and for Streptococcus mutans.

KEY WORDS: DENTURE STOMATITIS, DENTURE ADHESIVE, LACTOBACILLUS , CANDIDA ALBICANS, STREPTOCOCCUS MUTANS.

\section{ARTICLE INFORMATION}

*Corresponding Author: muralidharan@saveetha.com

Received 14th June 2020 Accepted after revision 9th August 2020

Print ISSN: 0974-6455 Online ISSN: 2321-4007 CODEN: BBRCBA

Thomson Reuters ISI Web of Science Clarivate Analytics USA and Crossref Indexed Journal

$$
\begin{aligned}
& \text { Clarivate } \\
& \text { Analytics }
\end{aligned}
$$

NAAS Journal Score 2020 (4.31) SJIF: 2020 (7.728)

A Society of Science and Nature Publication,

Bhopal India 2020. All rights reserved.

Online Contents Available at: http//www.bbrc.in/

Doi: http://dx.doi.org/10.21786/bbrc/13.7/76 


\section{INTRODUCTION}

In the fast moving world, most people are worried about aesthetics. In dentition, the doctors provide at most care to the patients to give better treatment and to achieve their satisfaction. This level of aesthetics especially in dentistry provides the patients the confidence to face the world (Manipal et al., 2014). Thus the denture usage by the patients has increased much. As an irony we know that every has an adverse effect, denture wearers also face a common problem known as denture stomatitis (Reichart, 2000). Denture Stomatitis is a common issue in denture wearers. It is mainly due to the continued use of the dentures. The Denture stomatitis is a chronic disease that is given by a localised or generalised inflammation of the oral mucosa beneath the dentures (Gendreau and Loewy, 2011).

Although this disease has a high frequency level in recent times, the patients who feel the burning, itching, and pain sensation are comparatively less and the disorder is only primarily diagnosed by the presence of the inflammation condition in the mucosal tissue (BUDTZ-JöRGENSEN, 1974). This disorder is mainly caused by the microorganisms commonly found in the oral cavity which includes Lactobacillus, Streptococcus mutans, Candida albicans. The denture adhesives are the ideal cream or paste that are used over the dentures to provide grip for the dentures to hold through. These denture adhesives provide a neutral or slightly basic $\mathrm{pH}$, cytotoxicity and bonding strength to the oral mucosa (Zhao et al., 2004; Ashwin and Muralidharan, 2015).

The denture adhesives is thus most commonly prescribed by the dentist as it renders additional retention, comfort and mastication facility for the dentures and inhibits the accumulation of food debris in the space between the dentures (Kumar et al., 2015). However this denture adhesives should not be used in a patient where the denture is completely ill-fitting and under such conditions more denture adhesives will be suggested to provide retention, which is not advised. Thus the usage of denture adhesives is provided to patients with correct doses and proportion for optimum results. These denture adhesives are available in powder, cream, or liquid form. It was first discovered in 1913 and developed in the 1920s and 30s (Shamsolketabi and Nili, 2018). Denture adhesives also provide a confidence for the patients to face the external world especially during the public occasions (Slaughter, Katz and Grasso, 1999; Shahana and Muralidharan, 2016).

Hence the denture adhesive activity on antibacterial property after placing in the oral cavity against the oral pathogens and preventing its harmful effect are measured to know its activity against bacterial species according to the previous research (Imazato et al., 2003),(Selvakumar and Np, 2017). And moreover if the denture adhesives provide biocompatibility and have Anti-Candida action, even used for a short period of time render a great effect in treating denture stomatitis and providing a better treatment measure (Bates et al., 2017). Thus the denture adhesives are materials that produce enormous results in dentistry and now in this study, its effect on the oral pathogens are tested and its antimicrobial activity is measured.

Figure 1: Denture adhesives used.

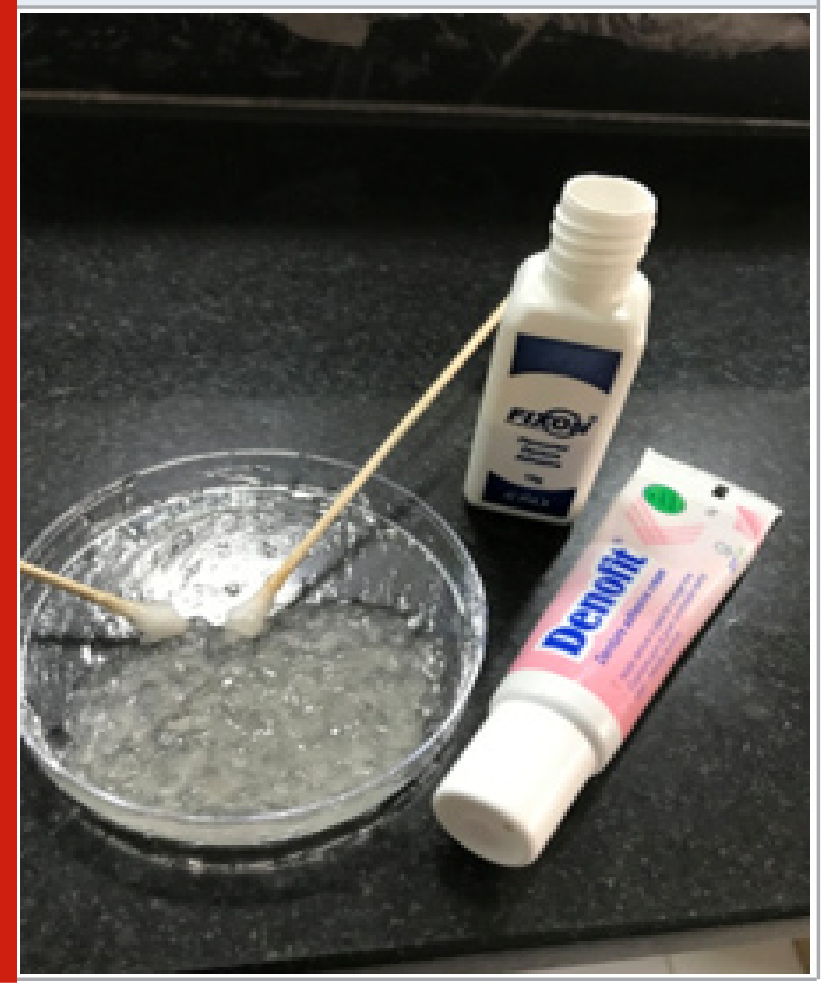

MATERIAL AND METHODS

In this study, the denture adhesive which is of powder and paste form was taken. The denture adhesives used in this study were Fixon (powder), Denofit (gel) (Figure 1). The powder was taken in sterile petri dishes, and 5 $\mathrm{ml}$ of distilled water was added. It is then mixed nicely with a sterile stick and held for 5 hours. The mix is kept separately so that it is not contaminated. In the same way the paste form of denture adhesive is also placed in a separate sterile petri plate and kept separately to prevent it from contamination. These plates were isolated because of swelling action of the denture adhesives. Well diffusion method: The anti microbial activity was tested by agar well diffusion method. The media used are SDA agar and TSA. Wells were cut with a sterile steel tube. TSA was used for Lactobacilli and S. mutans and SDA was used for C.albicans. On each plate 3 wells were cut and the adhesives were filled in it. The adhesives were mixed in sterile Petri plates and allowed to expand. Thus it was transferred to the well after coating the agar surface with the organism (figure 2). Then the plates were incubated at 37 degree $\mathrm{C}$ for $12 \mathrm{hrs}$ and examined for the zone of inhibition around the well. The zone was measured with a scale and tabulated. 
Figure 2: Denture adhesive transferred to petri plates.

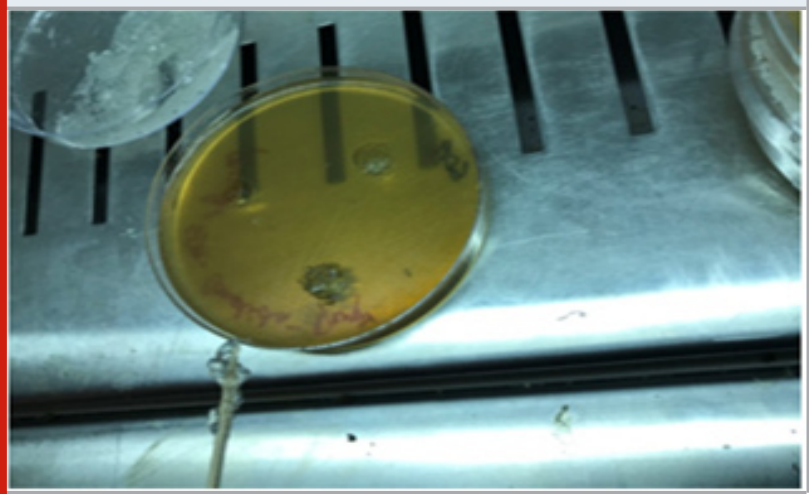

Figure 3: Antimicrobial activity of denture adhesive powder against Lactobacillus.

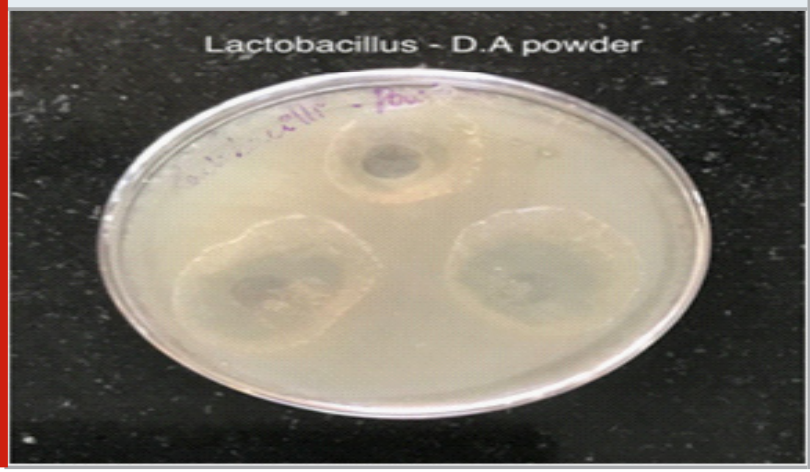

Figure 4: Antimicrobial activity of denture adhesive powder against C. albicans.

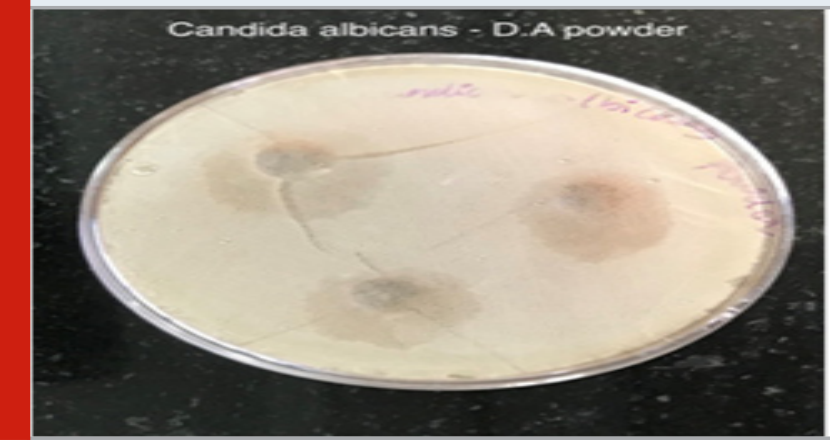

Figure 5: Antimicrobial activity of denture adhesive powder against S.mutans

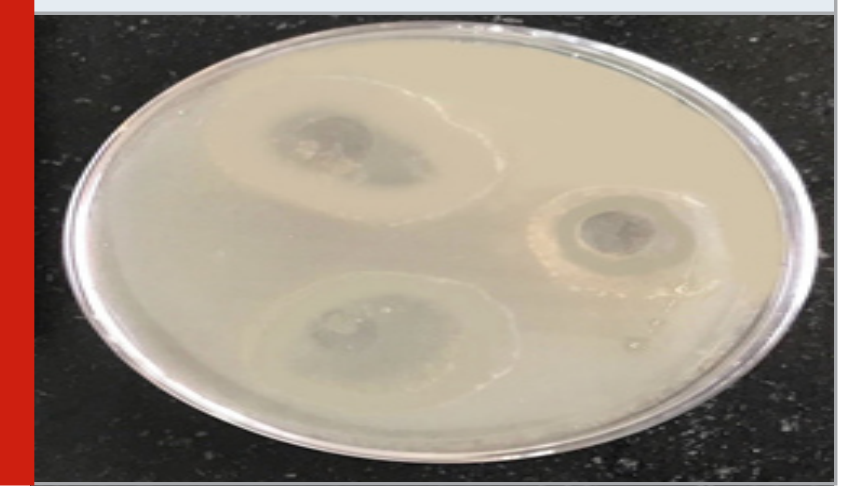

\section{RESULTS AND DISCUSSION}

The obtained results for the antimicrobial activity are shown in the table 1, bar graph 1 and in figure 3, 4 and 5. Thus the tabulated results (table 1) for the denture adhesive obtained as for powder the zone of inhibition in Lactobacillus was $11 \mathrm{~mm}$, zone of inhibition of powder in Candida albicans was $14 \mathrm{~mm}$ and the zone of inhibition for Streptococcus mutans was $10.5 \mathrm{~mm}$ which showed a better antimicrobial activity whereas for gels the zone of inhibition was not seen (bar graph 1). Thus in study we observe that the denture adhesive of powder form shows a better antimicrobial property than the paste form.

Table 1. Represents the microorganisms and the corresponding mean valve of antimicrobial activity in $\mathrm{mm}$ of denture adhesives.

\begin{tabular}{|l|c|c|}
\hline & POWDER(mm) & GEL(mm) \\
\hline S.Mutans & 10.5 & 0 \\
\hline Lactobacilli & 11 & 0 \\
\hline C.Albicans & 14 & 0 \\
\hline
\end{tabular}

Bar graph 1: This bar graph represents the correlation between the micro organisms and their respective zone of inhibition for powder and gel forms of denture adhesives. Blue colour denotes the effect of powder form and red colour denotes the effect of gel form. $\mathrm{X}$-axis represents the microorganisms tested and Y-axis represents the zone of inhibition measured in $\mathrm{mm}$. As there is no antimicrobial activity seen with gel, red bar is not represented

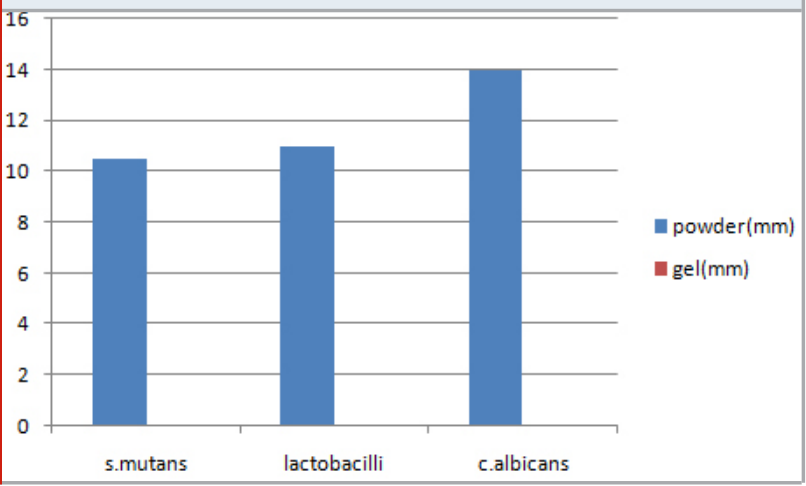

The human oral cavity contains various natural surroundings, including the teeth, gingival sulcus, tongue, hard and delicate palates, and tonsils, and acts the tract which associate the outside and the stomach related tract and respiratory tract of human body, which gives the fitting space to the colonization of microorganisms (Dodwad, 2011). The microorganisms found in the human oral pit have been alluded to as the oral microflora, oral microbiota, or oral microbiome (Dewhirst et al., 2010). Oral diseases may mess wellbeing up in immunocompromised hosts. Agent microorganisms in astute contaminations of 
the oral cavity are Staphylococcus aureus, Pseudomonas aeruginosa, and Candida albicans (Ding and Schloss, 2014). The denture adhesives are the retentive materials which are commonly used for providing retention in denture wearers (Shay, 1991,Nam et al., 2016). The antimicrobial property of these denture adhesives were analysed in both powder and gel forms.The denture adhesives involved in this study were Fixon (powder), Denofit (gel) (Figure 1). Thus the antimicrobial property comparison between the gel and the powder forms provided that the powder form had a higher antimicrobial property against the oral microorganisms than the gel form of denture adhesives.

\section{CONCLUSION}

In this study with the two products tested, powder has more antimicrobial activity than gel and found to be active against Lactobacillus, Candida albicans and for Streptococcus mutans. Powders can be recommended for patients who develop stomatitis.

\section{ACKNOWLEDGEMENTS}

We thank Saveetha Dental College for the support to conduct the research study.

\section{REFERENCES}

Ashwin, K. S. and Muralidharan, N. P. (2015) 'Vancomycin-resistant enterococcus (VRE) vs Methicillin-resistant Staphylococcus Aureus (MRSA)', Indian journal of medical microbiology, 33 Suppl, pp. 166-167. doi: 10.4103/0255-0857.150976.

Bates, A. M. et al. (2017) 'Diminished Antimicrobial Peptide and Antifungal Antibiotic Activities against Candida albicans in Denture Adhesive', Antibiotics (Basel, Switzerland), 6(1). doi: 10.3390/antibiotics6010006.

BUDTZ-JöRGENSEN, E. (1974) 'The significance of Candida albicans in denture stomatitis', European Journal of Oral Sciences, pp. 151-190. doi: 10.1111/ j.1600-0722.1974.tb00378.x.

Dewhirst, F. E. et al. (2010) 'The human oral microbiome', Journal of bacteriology, 192(19), pp. 5002-5017. doi: 10.1128/JB.00542-10.

Ding, T. and Schloss, P. D. (2014) 'Dynamics and associations of microbial community types across the human body', Nature, 509(7500), pp. 357-360. doi: $10.1038 /$ nature 13178 .

Dodwad, R. (2011) 'BENEFITS OF LIVE MICROORGANISMS IN ORAL HEALTH - A REVIEW', CODS Journal of Dentistry, pp. 15-16. doi: 10.5005/cods-3-2-15. Gendreau, L. and Loewy, Z. G. (2011) 'Epidemiology and Etiology of Denture Stomatitis', Journal of Prosthodontics, pp. 251-260. doi: 10.1111/j.1532849x.2011.00698.x.

Imazato, S. et al. (2003) 'Antibacterial activity and bonding characteristics of an adhesive resin containing antibacterial monomer MDPB', Dental Materials, pp. 313-319. doi: 10.1016/s0109-5641(02)00060-x.

Kumar, P. R. et al. (2015) 'Denture Adhesives in Prosthodontics: An Overview', Journal of international oral health : JIOH, 7(Suppl 1), pp. 93-95. Available at: https://www.ncbi.nlm.nih.gov/pubmed/26225115.

Manipal, S. et al. (2014) 'The importance of dental aesthetics among dental students assessment of knowledge', Journal of International Society of Preventive and Community Dentistry, p. 48. doi: 10.4103/2231-0762.131266.

Nam, S.-H. et al. (2016) 'Antimicrobial Activity of Propolis on Different Oral Bacteria', Indian Journal of Science and Technology. doi: 10.17485/ijst/2015/ v8i36/89174.

Reichart, P. A. (2000) 'Oral mucosal lesions in a representative cross-sectional study of aging Germans', Community Dentistry and Oral Epidemiology, pp. 390398. doi: 10.1034/j.1600-0528.2000.028005390.x.

Selvakumar, R. and Np, M. (2017) 'COMPARISON IN BENEFITS OF HERBAL MOUTHWASHES WITH CHLORHEXIDINE MOUTHWASH: A REVIEW', Asian Journal of Pharmaceutical and Clinical Research, p. 3. doi: 10.22159/ajpcr.2017.v10i2.13304.

Shahana, R. Y. and Muralidharan, N. P. (2016) 'Efficacy of mouth rinse in maintaining oral health of patients attending orthodontic clinics', Research Journal of Pharmacy and Technology, p. 1991. doi: 10.5958/0974360x.2016.00406.6.

Shamsolketabi, S. and Nili, M. (2018) 'The effect of denture adhesive on the efficiency of complete denture in patients with different alveolar ridges', Dental research journal, 15(4), pp. 271-275. Available at: https://www.ncbi.nlm.nih.gov/pubmed/30123304.

Shay, K. (1991) 'Denture adhesives. Choosing the right powders and pastes', Journal of the American Dental Association , 122(1), pp. 70-76. Available at: https:// www.ncbi.nlm.nih.gov/pubmed/1999589.

Slaughter, A., Katz, R. V. and Grasso, J. E. (1999) 'Professional attitudes toward denture adhesives: A Delphi technique survey of academic prosthodontists', The Journal of prosthetic dentistry, 82(1), pp. 80-89. doi: 10.1016/s0022-3913(99)70131-9.

Zhao, K. et al. (2004) 'Laboratory evaluation of a new denture adhesive', Dental materials: official publication of the Academy of Dental Materials, 20(5), pp. 419-424. doi: 10.1016/j.dental.2002.12.001. 